\title{
Water-Soluble Organic Aerosol material and the light-absorption characteristics of aqueous extracts measured over the Southeastern United States
}

\author{
A. Hecobian ${ }^{1}$, X. Zhang ${ }^{1}$, M. Zheng ${ }^{1}$, N. Frank ${ }^{2}$, E. S. Edgerton ${ }^{3}$, and R. J. Weber ${ }^{1}$ \\ ${ }^{1}$ Georgia Institute of Technology, School of Earth and Atmospheric Sciences, Atlanta, Georgia, USA \\ ${ }^{2}$ Office of Air Quality Planning \& Standards, US Environmental Protection Agency, 109 TW Alexander Drive, Research \\ Triangle Park, NC, USA \\ ${ }^{3}$ Atmospheric Research and Analysis, Inc, Durham, North Carolina, USA
}

Received: 3 March 2010 - Published in Atmos. Chem. Phys. Discuss.: 23 March 2010

Revised: 24 June 2010 - Accepted: 27 June 2010 - Published: 2 July 2010

\begin{abstract}
Light absorption of fine particle $\left(\mathrm{PM}_{2.5}\right)$ aqueous extracts between wavelengths of 200 and $800 \mathrm{~nm}$ were investigated from two data sets: 24-h Federal Reference Method (FRM) filter extracts from 15 Southeastern US monitoring sites over the year of 2007 (900 filters), and online measurements from a Particle-Into-Liquid Sampler deployed from July to mid-August 2009 in Atlanta, Georgia. Three main sources of soluble chromophores were identified: biomass burning, mobile source emissions, and compounds linked to secondary organic aerosol (SOA) formation. Absorption spectra of aerosol solutions from filter extracts were similar for different sources. Angstrom exponents were $\sim 7 \pm 1$ for biomass burning and non-biomass burning-impacted 24h filter samples (delineated by a levoglucosan concentration of $50 \mathrm{ng} \mathrm{m}^{-3}$ ) at both rural and urban sites. The absorption coefficient from measurements averaged between wavelength 360 and $370 \mathrm{~nm}\left(\mathrm{Abs}_{365}\right.$, in units $\mathrm{m}^{-1}$ ) was used as a measure of overall brown carbon light absorption. Biomass-burning-impacted samples were highest during winter months and $\mathrm{Abs}_{365}$ was correlated with levoglucosan at all sites. During periods of little biomass burning in summer, light absorbing compounds were still ubiquitous and correlated with fine particle Water-Soluble Organic Carbon (WSOC), but comprised a much smaller fraction of the WSOC, where $\mathrm{Abs}_{365}$ /WSOC (i.e., mass absorption efficiency) was typically $\sim 3$ times higher in biomass burningimpacted samples. Factor analysis attributed $50 \%$ of the
\end{abstract}

Correspondence to: R. J. Weber (rweber@eas.gatech.edu) yearly average $\mathrm{Abs}_{365}$ to biomass burning sources. Brown carbon from primary urban emissions (mobile sources) was also observed and accounted for $\sim 10 \%$ of the regional yearly average Abs 365 . Summertime diurnal profiles of Abs 365 and WSOC showed that morning to midday increases in WSOC from photochemical production were associated with a decrease in $\mathrm{Abs}_{365} / \mathrm{WSOC}$. After noon, this ratio substantially increased, indicating that either some fraction of the nonlight absorbing fresh SOA was rapidly (within hours) converted to chromophores heterogeneously, or that SOA from gas-particle partitioning later in the day was more lightabsorbing. Factor analysis on the 24-h integrated filter data associated $\sim 20$ to $30 \%$ of $\mathrm{Abs}_{365}$ over 2007 with a secondary source that was highest in summer and also the main source for oxalate, suggesting that aqueous phase reactions may account for the light-absorbing fraction of WSOC observed throughout the Southeastern US in summer.

\section{Introduction}

Carbonaceous species are a significant fraction of ambient fine aerosols and can have many chemical forms. Since comprehensive speciation has not been possible, grouping these compounds by physicochemical properties has been an effective means of characterizing their sources, impacts and atmospheric fate (Sullivan et al., 2004; Zhang et al., 2005; Decesari et al., 2000). Based on thermal and optical properties, carbonaceous aerosols are often divided into elemental carbon (EC) and organic carbon (OC) (Turpin et al., 1990; Birch and Carey, 1996), with the delineation a function of

Published by Copernicus Publications on behalf of the European Geosciences Union. 
the measurement method (e.g., thermal/optical transmission, TOT, versus thermal/optical reflectance, TOR) (Chow et al., 2004). EC (graphitic carbon) is refractory and highly light absorbing (Seinfeld and Pankow, 2003). When measured based on light absorption, this graphitic component is referred to as black carbon (BC) (Hansen and Novakov, 1990). Soot is also a term used for light absorbing carbon. However, soot can include black carbon and other adsorbed organic species that may or may not absorb light. EC is directly emitted from most combustion processes (Seinfeld and Pankow, 2003) and often internally mixed with other combustion products.

Organic aerosol (as measured by organic carbon mass, OC) includes a vast array of chemical species (Hamilton et al., 2004) that can have both primary and secondary sources. OC has been divided into a number of sub-groups, such as pure hydrocarbon organic aerosol (HOA) versus oxygenated organic aerosol (OOA) (Zhang et al., 2005). This categorization tends to follow the classification of water-insoluble organic carbon (WIOC) and water-soluble organic carbon (WSOC), respectively (Kondo et al., 2007; Miyazaki et al., 2006). WIOC has been found to be mainly from primary emissions (Miyazaki et al., 2006; Hennigan et al., 2009), which includes combustion of both fossil and biomass fuels. WSOC can be emitted directly from sources (primary emissions) or result from atmospheric processes (secondary sources). Biomass burning is a significant primary source of WSOC (with small contributions from fossil fuel burning) (Sullivan et al., 2006; Yan et al., 2009), and gas-to-particle conversion processes in which volatile organic compounds (VOCs) are oxidized to semi-volatile forms that partition to the aerosol (e.g., SOA formation) are a significant secondary source for WSOC (Sullivan et al., 2006; Miyazaki et al., 2006; Weber et al., 2007).

WSOC has been further divided by other physicochemical properties. A common sub-classification has been based on Solid Phase Extraction techniques that segregate WSOC into more hydrophilic (soluble) versus more hydrophobic (less soluble) components (Duarte et al., 2005; Graber and Rudich, 2006; Sullivan and Weber, 2006a). The more hydrophobic components have been found to have properties that include, higher molecular weight (Kiss et al., 2003), ability to cause surface tension depression (Facchini et al., 2000; Asa-Awuku et al., 2008) and light absorption (Havers et al., 1998; Varga et al., 2001; Hoffer et al., 2006), and are referred to as Humic-Like Substances (HULIS) (see (Graber and Rudich, 2006) for a review).

Black carbon (BC) has been recognized and extensively studied as the strongest light-absorbing component of aerosols, especially in the visible and near infrared region (400 to $700 \mathrm{~nm}$ wavelength range) (Bond, 2001; Rosen et al., 1980). Mineral dust and some organic aerosol components also absorb light (Yang et al., 2009). As a group, lightabsorbing organic aerosols have been referred to as Brown Carbon (Andreae and Gelencser, 2006) since they are com- posed of compounds that are most absorbing near the UV region of the UV-Vis spectrum.

A variety of studies have investigated sources of brown carbon. Incomplete and smoldering combustion of hydrocarbons, especially that associated with biomass burning, is known to directly produce particulate brown carbon (Duarte et al., 2005; Hoffer et al., 2006; Lukacs et al., 2007). There is also evidence based on ambient studies for a secondary source (Duarte et al., 2005; Marley et al., 2009) and laboratory studies show formation of chromophores (components of molecules that absorb light) through a variety of mechanisms, including ozonolysis of terpenes subsequently aged in the presence of ammonium ions and humidity (Bones et al., 2010), and a variety of additional aqueous phase reactions, such as lignin (Hoffer et al., 2004) and isoprene oxidation (Limbeck et al., 2003), and reactions of carbonyls (e.g., glyoxal, methyglyoxal) in acidic solutions (Noziere et al., 2007; Noziere and Esteve, 2005; Sareen et al., 2010), with amino acids (de Haan et al., 2009a; Noziere et al., 2007), methyl amines (de Haan et al., 2009b), or ammonium salts (Noziere et al., 2009; Sareen et al., 2010; Shapiro et al., 2009). These aqueous reactions not only produce brown carbon but also other characteristics associated with HULIS, such as higher molecular weight and surface-active properties (de Haan et al., 2009b; Shapiro et al., 2009; Sareen et al., 2010). A goal of this work was to gain insight on the chemical nature and processes that influence the ambient organic aerosol through measurements of light absorption and chemical properties of the water-extractable aerosol components.

\section{Methods}

Data were generated from two sources; archived Teflon filters collected at various sites throughout the Southeastern US in 2007, and from an online measurement system deployed from July to mid-August of 2009 in Atlanta, GA. In both cases, light absorption properties of water extracts containing dissolved aerosol components were measured with the same UV-Vis Spectrophotometer.

\subsection{Light absorption measurements}

Light absorption spectra of water-soluble aerosol components were measured with a UV-Vis Spectrophotometer and Long-Path Absorption Cell. Liquid samples either from FRM filter extracts or the online system (Particle Into Liquid Sampler, PILS) were injected via syringe pumps into a 1-m path-length Liquid Waveguide Capillary Cell (LWCC2100, World Precision Instrument, Sarasota, FL), with an internal volume of $250 \mu \mathrm{L}$. A dual deuterium and tungsten halogen light source (DT-Mini-2, Ocean Optics, Dunedin, FL) and absorption spectrometer (USB4000 spectrometer, Ocean Optics, Dunedin, FL) were coupled to the wave-guide via fiber optic cables (QP400-2-SR, Ocean Optics, Dunedin, 


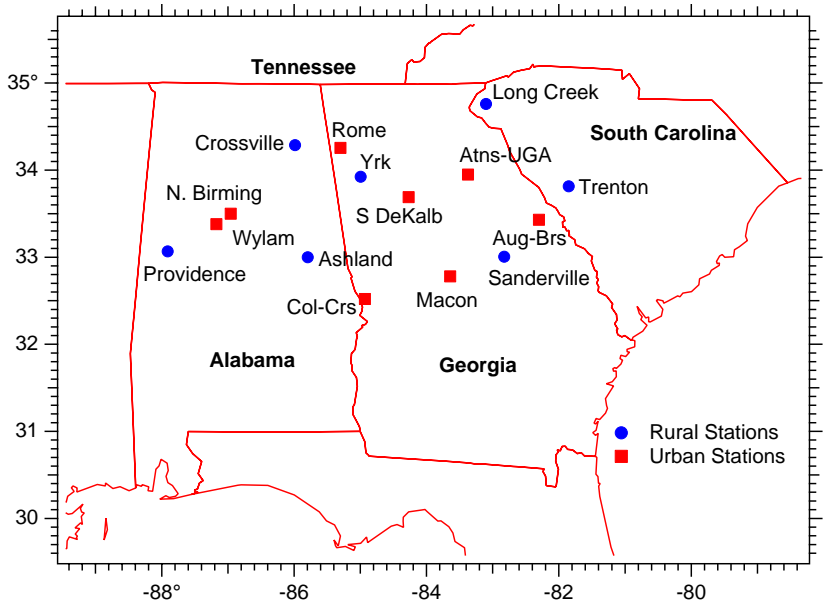

Fig. 1. Locations and designation (rural/urban) of FRM filter collection sites in Southeastern United States.

FL). Absorption spectra were recorded over a wavelength range of 200 to $800 \mathrm{~nm}$ with an Ocean Optics Spectra-Suite data acquisition software system (Ocean Optics, Dunedin, FL).

During operation, the system was cleaned with a $0.6 \mathrm{~N}$ solution of $\mathrm{HCl}$ and Milli-Q ( $>18 \mathrm{M} \Omega$ ) DI water after each filter aliquot analysis, and every three days for the online system (online samples were much more dilute requiring less frequent cleaning). Following cleaning, the baseline was zeroed using the Spectra-Suite software so that zero absorption was recorded at all wavelengths for milli-Q (>18 M $\Omega$ ) DI water.

\subsection{Filter measurements}

The Georgia Department of Natural Resources (DNR) routinely measures ambient aerosol $\mathrm{PM}_{2.5}$ mass at sites located throughout the state following a Federal Reference Method protocol. This involves collecting particles on $46.2 \mathrm{~mm}$ Teflon filters (Pall-Life Science, Ann Arbor, MI) using a fine particulate cyclone size selector and non-denuded sampler operating for 24 hours at a flow rate of $16.7 \mathrm{~L} \mathrm{~min}^{-1}$. At many sites these filters were collected every six days, subsequently weighed to determine mass concentrations and archived. Other states in the region follow a similar protocol. In 2008, archived filters for the year of 2007 were obtained for a range of sites from the Georgia DNR, the South Carolina Department of Health and Environmental Control and the Alabama Department of Environmental Management and Jefferson Co. (Alabama) Department of Health. Sites were chosen to include a range of rural and urban locations spread throughout the Southeastern US (Fig. 1, Table 1). An everysixth day sampling frequency at each site resulted in 60 filters per site and a total of 900 filters for analysis for the year 2007. Filters were shipped from the monitoring stations in coolers with blue ice and then immediately transferred to a freezer
Table 1. Names and locations of the FRM sampling sites used in this study. A map is provided in Fig. 1. A subset of the sites were also speciation sites $\left(^{*}\right)$ with additional measurements of aerosol components (e.g., OC, EC, and metals).

\begin{tabular}{llll}
\hline Site Location (Abbreviation) & $\begin{array}{l}\text { Urban/ } \\
\text { Rural }\end{array}$ & Latitude & Longitude \\
\hline Ashland & $\mathrm{R}$ & 33.2849 & -85.8036 \\
Athens (Atns-UGA)* $_{\text {Augusta (Aug-Brs)* }}^{*}$ & $\mathrm{U}$ & 33.9179 & -83.3446 \\
Birmingham (N Birming) $^{*}$ & $\mathrm{U}$ & 33.4339 & -82.0224 \\
Columbus (Col-Crs) $^{*}$ & $\mathrm{U}$ & 33.5530 & -86.8149 \\
Crossville $_{\text {Decatur (S. DeKalb) }}$ & $\mathrm{U}$ & 32.4309 & -84.9318 \\
Long Creek $_{\text {Macon* }}$ & $\mathrm{R}$ & 34.2886 & -85.9699 \\
Providence & $\mathrm{U}$ & 33.6881 & -84.2902 \\
Rome* & $\mathrm{R}$ & 34.8053 & -83.2377 \\
Sandersville & $\mathrm{U}$ & 32.7773 & -83.6412 \\
Trenton & $\mathrm{R}$ & 33.4596 & -87.3055 \\
Wylam $_{\text {Yorkville (Yrk) }}^{\mathrm{U}}$ & 34.2611 & -85.3230 \\
& $\mathrm{R}$ & 32.9747 & -82.8089 \\
\hline
\end{tabular}

(nominally $-10^{\circ} \mathrm{C}$ ) where they were stored until analysis. Thus, these filters had been in storage at below freezing temperatures for approximately one year prior to analysis. Zhang et al. (2010a) provides an overview of the study and methods used to extract and analyze these filters.

Filters were extracted in $30 \mathrm{~mL}$ of $>18 \mathrm{M} \Omega$ Milli-Q water (Barnstead Nanopure System, Thermo Scientific, Weltham, MA) in $30 \mathrm{~mL}$ amber Nalgene HDPE bottles with screw top lids that had been triple-rinsed. Liquid was extracted from the bottle with a $5 \mathrm{~mL}$ disposable (HDPE) syringe and transferred to another $30 \mathrm{~mL}$ amber bottle and filtered using a $0.45 \mu \mathrm{m}$ PTFE disposable syringe filter. The bottles were stored in the dark at $4{ }^{\circ} \mathrm{C}$ until analysis, typically completed within 2 to 3 days following extraction. Aliquots of sample were taken from the bottle for a series of analysis.

A Dionex (Sunnyvale, CA) ion chromatography system (DX-500), LC25 Chromatography Oven, GP40 Gradient Pump and ED50 Electrochemical Detector were used for the measurement of a range of carbohydrates, including levoglucosan, a biomass-burning tracer (e.g., Puxbaum et al., 2007). The mobile phase eluent was made from $50 \% \mathrm{v} / \mathrm{v}$ sodium hydroxide $(\mathrm{NaOH})$ stock solution. The solution was degassed by purging with ultra pure helium for 30 minutes before the beginning of daily measurements. Separations were achieved with a Dionex CarboPac PA-1 column and gradient mobile phase as follows: $7.2 \mathrm{mM} \mathrm{NaOH}$ for the initial seven minutes, $7.2 \mathrm{mM} \mathrm{NaOH}$ ramp to $72 \mathrm{mM} \mathrm{NaOH}$ from the 8 th to the 25 th min, $180 \mathrm{mM} \mathrm{NaOH}$ from 28th to 43rd minutes to clean the column and $7.2 \mathrm{mM} \mathrm{NaOH}$ from the $43^{\text {rd }}$ to the 
59th minute to achieve column re-equilibrium. Samples were loaded unto the PA-1 column from a $100 \mu \mathrm{L}$ sample loop. Carbohydrate standards were made from stock solutions of solid dissolved in Milli-Q DI water. Complete calibrations were repeated three times during the study and in all cases the $r^{2}$ values were greater than 0.99 and slope variability ranged from 2 to $25 \%$ for the various compounds. Even though the PA-1 column provided the peak separation for many of the carbohydrates of interest, levoglucosan and arabitol co-eluted (Iinuma et al., 2009). The correction for the co-elution of arabitol and levoglucosan was accomplished by using mannitol, which has a strong linear correlation with arabitol (Zhang et al., 2010a).

Water-soluble organic carbon (WSOC) concentration of filter extracts was determined in $10 \mathrm{~mL}$ aliquots using a Sievers Total Organic Carbon (TOC) Analyzer (Model 900, GE Analytical Instruments; Boulder, CO). The TOC analyzer was calibrated at the beginning and near the end of the measurements with a series of sucrose standards (linear regression $r^{2}=0.9997, N=5$ ).

For the absorption measurements, an automated multiport syringe (Klohn, LTD; Las Vegas, NV) was programmed to inject $1 \mathrm{~mL}$ of sample into the $0.25 \mathrm{~mL}$ LWCC. Complete absorption spectra were recorded 30 seconds after the injection of the aliquot. Following each measurement, the LWCC was flushed with $1 \mathrm{~mL}$ of a $0.6 \mathrm{~N}$ solution of $\mathrm{HCl}$ and $3 \mathrm{~mL}$ of Milli-Q DI water.

A series of field and laboratory blanks, and laboratory prepared standards, were also analyzed during analysis to assess interferences and measurement precision. Field blank filters ere analyzed as regular filters. For every 10th filter in the sample queue, a water blank and a single standard (a range of standards were used) were analyzed. The limit of detection (LOD) of WSOC was calculated from $3 \sigma$ (standard deviation) of the filter blanks, whereas LODs for the carbohydrates were calculated from $3 \sigma$ of the noise of the typical baseline of the IC system (field and water blanks had non-detectable levels of carbohydrates). The LOD for WSOC was $0.15 \mu \mathrm{gC}$ $\mathrm{m}^{-3}$, and ranged from 0.2 to $0.6 \mathrm{ng} \mathrm{m}^{-3}$ for the carbohydrates. Comparisons of concentrations from co-located filter measurements (measurement precision) were within $4 \%$ for WSOC and $13 \%$ for levoglucosan. Finally, measurement uncertainties were calculated as quadrature sum of relative errors associated with extraction water volume, variability in calibration standards, filter blanks and precision, resulting in $\pm 9 \%$ for WSOC and $\pm 21 \%$ for levoglucosan.

\subsection{Online measurements of WSOC and light absorp- tion}

An automated online system was constructed to provide semi-continuous measurements of both the absorption spectra and carbon mass of water-soluble aerosol components by adding a LWCC to a PILS-WSOC system (Fig. 2). In this instrument ambient particles are concentrated into a continuous

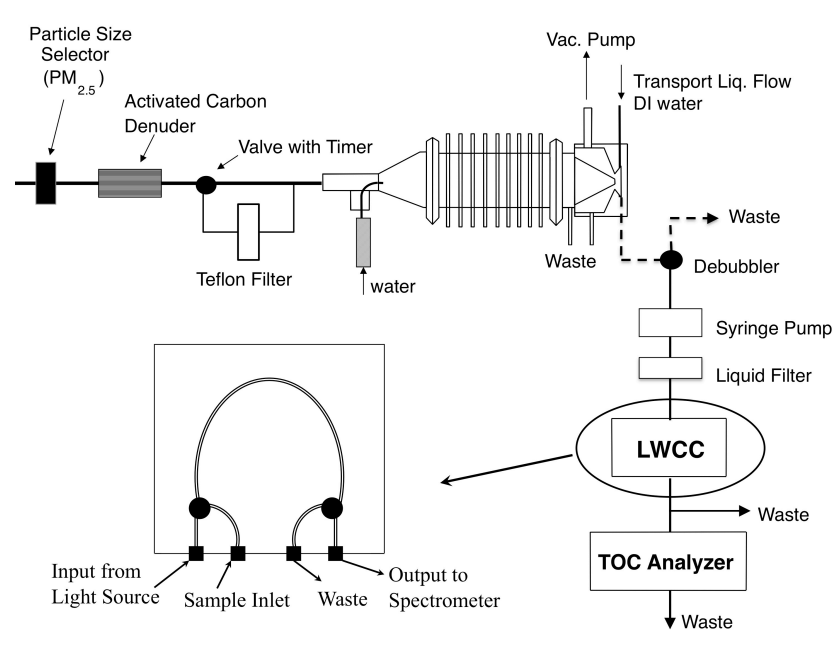

Fig. 2. Schematic of the online light absorption and WSOC measurement system.

flow of high purity water by a steam-condensation-droplet impaction collection system (Sullivan et al., 2004). Two syringe pumps with automated selection valves (Klohn, LTD.; Las Vegas, NV) continuously draw sample from the PILS through a debubbler and pump liquid sample at a nominal

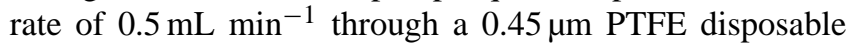
syringe filter followed by the LWCC and the TOC analyzer. The TOC analyzer was operated in normal mode (non-turbo), drawing sample into the detector at a flow rate of $0.4 \mathrm{~mL} / \mathrm{min}$ and recording average liquid carbon concentrations at a 6min duty cycle. Upstream of the PILS a non-rotating multiorifice impactor (MSP; Shoreview, MN) was used to exclusively sample $\mathrm{PM}_{2.5}$ aerosols. Possible positive artifacts due to interfering gases were reduced with an activated carbon denuder (Eatough et al., 1993) and a pre-programmed automated valve that shunted sample through a Teflon filter (PallLife Science, Ann Arbor, MI) to provide an automated blank. Subtraction of this blank accounted for possible interferences due to collection and analysis of any water-soluble organic gases and contaminants in the ultra-pure water used in this system. Complete absorption spectra were collected every five minutes and absorption data for selected wavelengths of interest $(250,365,400$ and $700 \mathrm{~nm})$ were collected every 20 seconds. Background measurements were performed twice per day (4:30 and 18:30 local time) for $45 \mathrm{~min}$, for the duration of the study. Ambient WSOC concentrations were determined by subtraction of blanks determined by a linear interpolation between consecutive blank measurements. The uncertainly of this system has been estimated at $8 \%$ and the limit of detection (LOD) $\sim 0.1 \mu \mathrm{gC} \mathrm{m} \mathrm{m}^{-3}$ (Sullivan et al., 2006). Figure 3 shows an example of non blank-corrected ambient WSOC (liquid) concentration and light absorption at 365 and $700 \mathrm{~nm}$ using the online PILS-LWCC-TOC system. Periods of dynamic blank measurements are evident in the figure in both the WSOC and absorption at $365 \mathrm{~nm}$. 


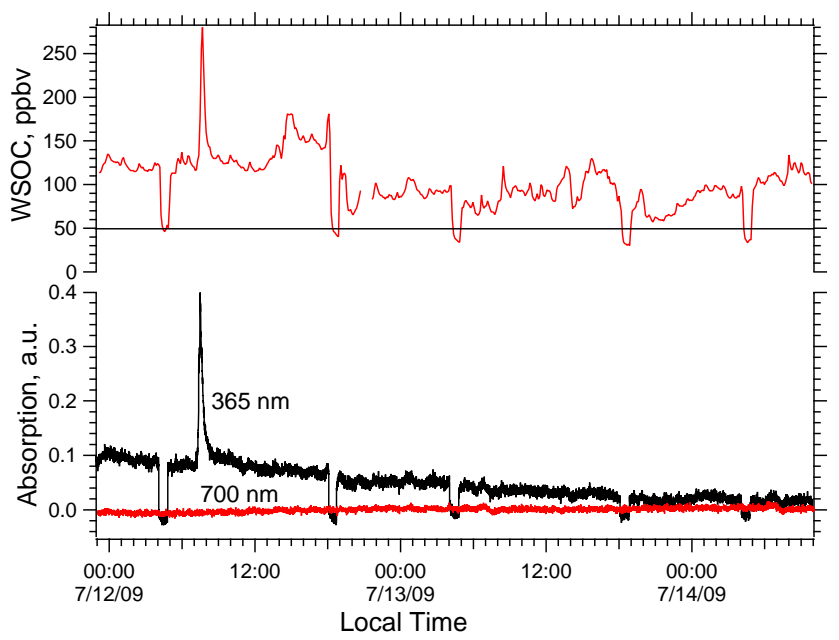

Fig. 3. Unprocessed Water-Soluble Organic Carbon (WSOC) and light absorption at two wavelengths (centered at 365 and $700 \mathrm{~nm}$ ) in Atlanta, GA. Measurements during periods of automated dynamic blank are evident in the WSOC and absorption at $365 \mathrm{~nm}$, but not at $700 \mathrm{~nm}$, the latter is used as a reference.

From 1 July to 15 August 2009, online water-soluble aerosol absorption measurements were performed in Atlanta, GA, with this system. The site was located in the Georgia Institute of Technology Ford Environment Sciences and Technology air quality laboratory situated on the building's top floor approximately 20 to $40 \mathrm{~m}$ above ground level (depending on the side of the building). This sight is a straight-line distance of roughly $840 \mathrm{~m}$ from a major interstate highway. A number of atmospheric chemistry studies have been published based on data from this location (e.g., Hennigan et al., 2009).

To assess any effect of adding an LWCC on WSOC measurements, Milli-Q water (18 M $\Omega$ ) and different solutions of oxalate were used to check for positive and negative artifacts. Background carbon levels increased from a typical concentration of $25 \mathrm{ppbv}$ to $50 \mathrm{ppbv}$. This background increase was accounted for in the blank corrections. The TOC response to oxalate solutions with the LWCC inline compared to offline did not change significantly (linear regression $r^{2}=0.998$, intercept $=5.6 \mathrm{ppbv}$, slope $=1.07$ and $\mathrm{N}=6$ ), indicating no adverse effect on the WSOC concentrations.

\subsection{Interpretation of solution absorption data}

Light absorption measured by the spectrophotometer as the $\log$ base-10 of intensity of transmitted $(I)$ to incident $\left(I_{0}\right)$ light at a given wavelength $\left(A_{\lambda}\right)$ follows Beer's Law,

$A_{\lambda}=-\log _{10}\left(I / I_{0}\right)=l \cdot C \cdot \varepsilon=l \sum_{i}\left(C_{i} \cdot \varepsilon_{i}\right)=l \cdot \mathrm{Abs}_{l}$

Where the measured absorption $A_{\lambda}$ is linearly dependant on the concentration of light absorbers in solution $(C)$, their mass absorptivities ( $\varepsilon$ also call mass absorption efficiency), and absorbing path length $(l)$. For solutions containing multiple types of chromophores, the light absorption recorded is the sum of all chromophore concentrations times their mass absorptivity over all species $(i)$, and is referred to as the light absorption coefficient $\left(\mathrm{Abs}_{l}\right.$, where here $l$ denotes a liquid sample). Zeroing over all wavelengths with pure water blanks (the solvent) accounts for any absorption not due to chromophores in solution. In this study, to account for baseline drift during analysis periods (e.g., between solution zeroing), absorption for all wavelengths were referenced to absorption at $700 \mathrm{~nm}$ (mean between 695 and $705 \mathrm{~nm}$ ) where there was no absorption for ambient aerosol solutions (see Fig. 3). To convert the absorption coefficient due to chromophores measured in solution to ambient aerosol chromophore concentrations, which depend on the particle collection method (e.g., FRM-filter and PILS), and referencing to absorption at 700nm to account for any drift, all absorption data in this study were converted to an absorption coefficient at a given wavelength $\left(\mathrm{Abs}_{\lambda}\right)$ by:

$\operatorname{Abs}_{\lambda}=\left(A_{\lambda}-A_{700}\right) \frac{V_{l}}{V_{a} \cdot l} \cdot \ln (10)$

where $V_{l}$ is the volume of water the filter was extracted into $(30 \mathrm{~mL})$ or PILS liquid sample flow rate $\left(0.7 \mathrm{~mL} \mathrm{~min}^{-1}\right)$ and $V_{a}$ the volume of sample air that passed through the filter $\left(16.7 \mathrm{~L} \mathrm{~min}^{-1}\right.$ for $\left.24 \mathrm{~h}\right)$ or the PILS sample-air flow rate $\left(15 \mathrm{~L} \mathrm{~min}^{-1}\right)$. The absorbing path length is $0.94 \pm 0.01 \mathrm{~m}$, approximately the length of the 1-m wave-guide (Belz et al., 1999). The resulting absorption coefficient in units of $\mathrm{m}^{-1}$ was also converted from log base-10 to natural log to be consistent with how atmospheric measurements are typically reported.

Although the complete light absorption spectra were recorded from 200 to $800 \mathrm{~nm}$, for simplicity the absorption coefficients averaged between 360 to $370 \mathrm{~nm}\left(\mathrm{Abs}_{365}\right)$ were used as a general measure of the absorption by all aerosol chromophore components (absorption spectra are discussed below). This wavelength was chosen because it is far enough from the UV region to avoid interferences from non-organic compounds (e.g., nitrate) and is similar to what has been used in other studies (e.g., (Lukacs et al., 2007)). Furthermore, $\mathrm{Abs}_{365}$ is highly correlated to the sum of measured absorption over 300 to $400 \mathrm{~nm}(r=0.92)$. Brown carbon specifically associated with HULIS has been investigated in a number of other studies by first isolating HULIS from the filter aqueous extracts. This eliminates possible interferences from inorganic species, however, the analytical procedure is more complex and an online measurement is not possible. 


\section{Results}

\subsection{Absorption spectra}

The wavelength $(\lambda)$ dependence of particulate absorption is often fit with a power law of the form:

$\alpha_{a b}=K \cdot \lambda^{-\AA_{p}}$

Where $\alpha_{a b}$ is the aerosol mass absorption efficiency (or mass absorption cross-section), $K$ a constant related to aerosol mass concentration and $\AA_{p}$ is the particulate Ångstrom exponent for absorption that depends on particle size and composition (e.g., refractive index). An analogous equation can be used to describe the wavelength dependence for absorption by chromophores in solution, which depends only on the types of chromophores (e.g., $\varepsilon \sim \lambda^{-\AA}$, and so $\operatorname{Abs}_{\lambda} \sim \lambda^{-\stackrel{\circ}{A}}$.

In urban environments, where light absorption is dominated by soot, multi-wavelength absorption measurements for particles collected on filters show that $\AA_{p}$ is close to 1 (Bond, 2001; Kirchstetter et al., 2004), whereas values between roughly 1 and 2 were recorded for ambient biomass burning aerosols (Marley et al., 2009; Kirchstetter et al., 2004), and 3.5 for a polluted region in China impacted by coal and biomass burning emissions (Yang et al., 2009). In the case of aqueous samples $\AA \sim 7$ were recorded in watersoluble HULIS (Hoffer et al., 2006) extracted from the ambient aerosol in Amazonian biomass burning plumes, whereas values ranging from $\sim 7$ to 16 were recorded in laboratory generated smoke from smoldering wood of various types (Chen and Bond, 2010). Aqueous extracts of SOA produced from the ozonolysis of terpenes in the presence of ammonium produced $\AA \sim 7$ for fresh SOA and $\sim 4.7$ for more aged (days old) SOA (Bones et al., 2010).

Absorption spectra of aerosol compounds in the FRM filter extracts were analyzed in this study. Figure 4 shows $\mathrm{Abs}_{\lambda}$ versus wavelength for conditions of significant and insignificant biomass-burning for selected samples from an urban and rural site. To determine Ångstrom exponents, a linear regression fit was applied to the logarithms of $\mathrm{Abs}_{\lambda}$ and wavelength. The data were first smoothed with a running average of $\pm 5 \mathrm{~nm}$ and the range of the fit determined by the linear region of Abs $\lambda$ and wavelength on log-log plots (see Fig. 4). For the South DeKalb site the power law fit well over a range of 330 to $600 \mathrm{~nm}$. For Yorkville data, the fit range was from 330 to $475 \mathrm{~nm}$ for levoglucosan less than $50 \mathrm{ng} \mathrm{m}^{-3}$ and 330 to $500 \mathrm{~nm}$ for levoglucosan greater than $50 \mathrm{ng} \mathrm{m}^{-3}$. In all cases this resulted in fits that were better than $r=-0.99$. Ångstrom exponents from this analysis ranged from approximately 6 to 8 indicting no significant difference between biomass burning samples and samples from summer when biomass burning was generally negligible, or between urban or rural sites. (If all curves are fit over the same wavelength range of 330 to $500 \mathrm{~nm}$, Ångstrom exponents remain largely
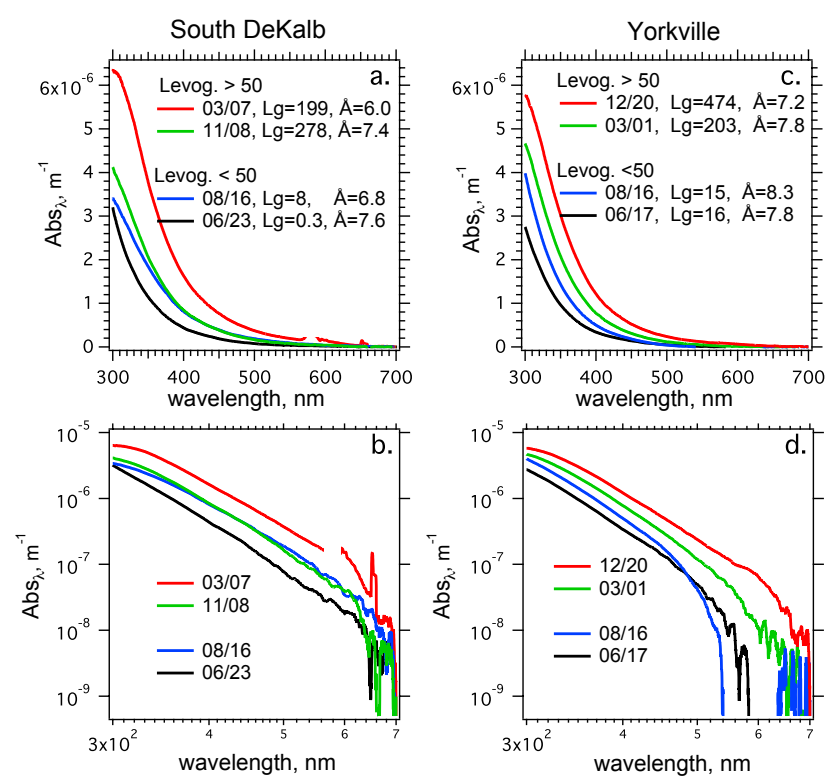

Fig. 4. Examples of absorption spectra from FRM filters collected at a representative urban, (South Dekalb, (a) and (b)) and rural (Yorkville, (c) and (d)) site for biomass burning (levoglucosan $>50 \mathrm{ng} \mathrm{m}^{-3}$ ) and non-biomass burning (levoglucosan $<50 \mathrm{ng} \mathrm{m}^{-3}$ ) periods. Sample date (MM/DD) of 2007, levoglucosan concentraction $\left(\mathrm{ng} \mathrm{m}^{-3}\right)$, and the Ångstrom exponents $(\AA)$ are given. These sampling days are also identified in Fig. 6.

unchanged with a maximum difference of $9 \%$ and span the range of 6.2 to 8.3). These Ångstrom exponents are similar to those of biomass burning HULIS ( $\AA \sim 7.1)$ (Hoffer et al., 2006) and fresh aqueous extracts of terpene ozonolysis SOA ( $\AA \sim 7)$ (Bones et al., 2010).

\subsection{FRM filter results}

\subsubsection{Seasonal trends and comparisons between winter and summer}

As in other studies, the FRM filter data demonstrated that biomass burning was a significant source for brown carbon. Figure 5 shows the median WSOC, levoglucosan, and absorption coefficient $\left(\mathrm{Abs}_{365}\right)$ for all sites. A detailed analysis demonstrating that levoglucosan was a reasonable biomassburning tracer throughout the year for this data set is reported elsewhere (Zhang et al., 2010a). Highest contributions from biomass burning (as indicated by levoglucosan) were observed in the winter months (November through March). In 2007 extensive burning episodes over a broad region of Southern Georgia resulted in smoke impacts over much of the Southeast and accounted for the high WSOC variability (error bars) in May 2007 (see (Zhang et al., 2010a) for more details). In a general sense, the absorption coefficient $\left(\mathrm{Abs}_{365}\right)$ had a similar seasonal trend as biomass burning emissions, and an analysis of $\mathrm{Abs}_{365}$ and levoglucosan 


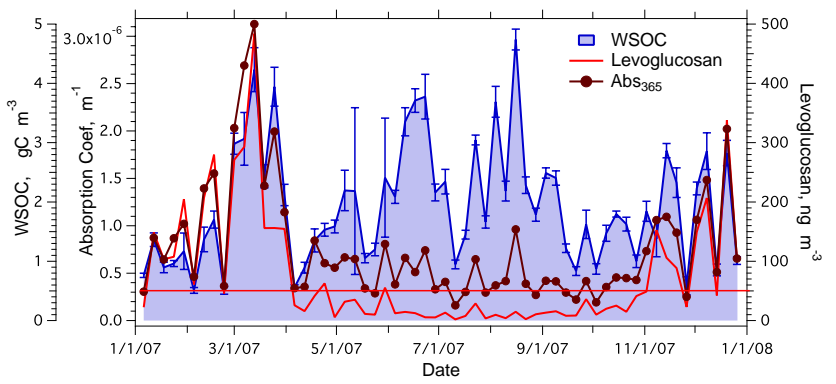

Fig. 5. Median fine particle $\left(\mathrm{PM}_{2.5}\right)$ Water-Soluble Organic Carbon (WSOC), levoglucosan and light absorption coefficient at $365 \mathrm{~nm}$ (Abs365) averaged over all 15 FRM sites shown in Fig. 1. WSOC error bars are the WSOC standard error. The cutoff of $50 \mathrm{ng} \mathrm{m}^{-3}$ for a biomass-burning influence is shown as a horizontal line.

at individual sampling sites showed that they were highly correlated at both urban and rural locations when samples were impacted by biomass burning (Fig. 6). This trend was observed at most sites. For example, when levoglucosan was greater than $50 \mathrm{ng} \mathrm{m}^{-3}$ for the 15 sites, (mostly winter months, Fig. 5), mean correlation between $\mathrm{Abs}_{365}$ and levoglucosan was $r=0.9$.

Division of the FRM-filter data into biomass burning and non-biomass burning-influenced periods using levoglucosan concentrations of $50 \mathrm{ng} \mathrm{m}^{-3}$ was somewhat arbitrary; winter and summer mean levoglucosan concentrations were 170 and $19 \mathrm{ng} \mathrm{m}^{-3}$, respectively (Zhang et al., 2010a). Background levoglucosan concentrations in Europe have been reported to be in the range of 5 to $52 \mathrm{ng} \mathrm{m}^{-3}$ (Puxbaum et al., 2007).

In contrast to the colder periods at the beginning and end of the year, during the warmer seasons during the middle of the year both levoglucosan and Abs 365 were much lower (see Fig. 5); however, WSOC remained high, presumably due to secondary organic aerosol formation (Zhang et al., 2010a; Hennigan et al., 2009), which produced a significantly lower proportion of WSOC light-absorbing compounds (mass absorption efficiency) compared to biomass burning. Figure 6 shows the difference in fraction of light-absorbing species to total WSOC (i.e., slopes of $\mathrm{Abs}_{365}$ vs. WSOC) during periods of high and low levoglucosan. Regression results for all sites are summarized in Table 2. For most sites, there was a high correlation $(r)$ between $\mathrm{Abs}_{365}$ and WSOC concentration, with mean $r \sim 0.84$ for biomass burning periods and $\sim 0.73$ for non-biomass burning (Table 2). On average, $\mathrm{Abs}_{365}$ relative to WSOC (based on regression slopes or average of $\mathrm{Abs}_{365}$ /WSOC ratios) at various monitoring stations demonstrate that for a given category (biomass-burning or non-biomass-burning) the average mass absorption efficiency was not highly variable between sites, with a relative variability (Std/Mean) less than $20 \%$ for biomass burning periods at both urban and rural sites and less than $30 \%$ for nonbiomass burning (slopes in Table $2 b$ ). In both cases, lower variability was observed at the rural sites. Overall, a com-
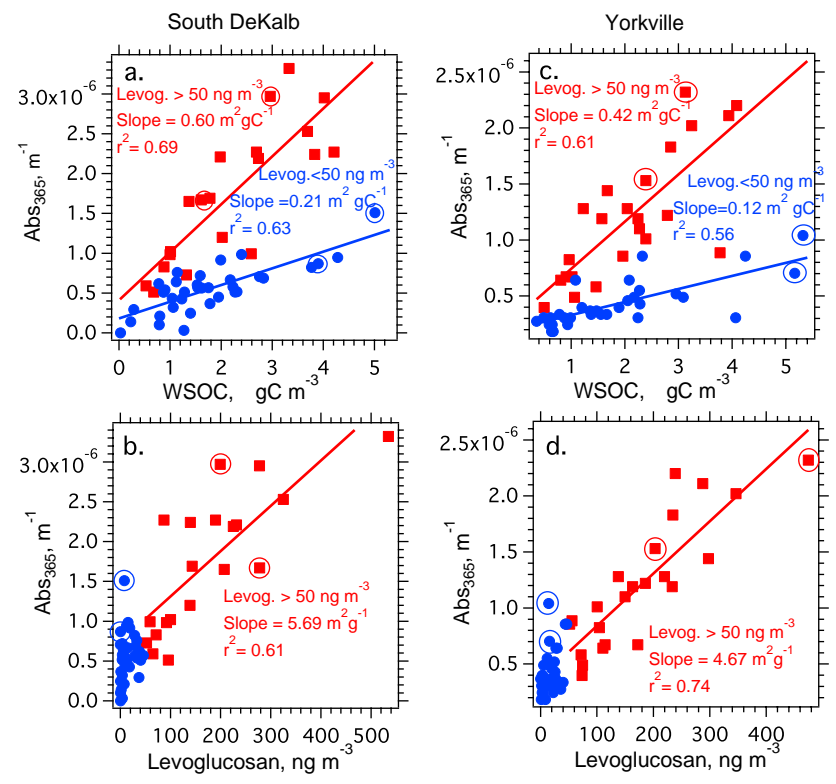

Fig. 6. Relationship between absorption coefficient at $365 \mathrm{~nm}$ (Abs365), WSOC and levoglucosan at a representative urban (South Dekalb, (a) and (b)) and rural (Yorkville, (c) and (d)) site. Absorption spectra for the circled data points are shown in Fig. 4.

parison between the two categories delineated by a levoglucosan of $50 \mathrm{ng} \mathrm{m}^{-3}$ shows that the Abs 365 per WSOC mass was approximately a factor of 3 times higher in the biomass burning-impacted samples versus the non-biomass-burning samples.

A reasonable correlation between $\mathrm{Abs}_{365}$ and WSOC $(r \sim 0.73)$ at each site throughout the Southeast indicates a regional light-absorbing component to WSOC that is not associated with biomass combustion sources since during summer most WSOC is from secondary sources and there was no correlation between $\mathrm{Abs}_{365}$ and levoglucosan.

\subsection{Factor analysis results}

Using the year-long FRM filter data set, Zhang et al., (2010a) undertook a statistical analysis to identify a small set of factors that could explain the observed temporal variability of aerosol components measured from the filters. Applying a factor analysis over large spatial and temporal scales using the pooled data set provided greater statistical power, but implies some degree of consistency in emissions and sources over these scales of space and time. The resolved source profiles (factors) are thus representative of the regional sources or processes that influenced variability in the selected components throughout the year. (Note that an analysis of rural or just urban sites results in nearly identical source profiles as the pooled data set). Here, only a brief discussion on the approach is provided, see Zhang et al. (2010a) for more details. Two analyses were performed: 1) Using the more limited number of components quantified from all FRM filters. 
Table 2a. Summary of Abs 365 to WSOC regression slopes and ratios in units of $\mathrm{m}^{2} \mathrm{gC}^{-1}$ (i.e., mass absorption efficiency) for each 24-h FRM filter site. Data from Long Creek are excluded due to spurious $\mathrm{Abs}_{365}$ measurements and regressions with low $r$ (AtnsUGA $r=0.33$ ) are not included in the statistical calculations. For each site classification (Urban or Rural) Sites are in descending order of Mean $\mathrm{Abs}_{365}$ /WSOC. N is the number of data points (filters). (a) Levoglucosan $>50 \mathrm{ng} \mathrm{m}^{-3}$ (mostly Winter data).

\begin{tabular}{lllllll}
\hline Urban Site & Slope & $r$ & Mean & Median & Stdev & $N$ \\
\hline S. DeKalb & 0.60 & 0.83 & 0.84 & 0.89 & 0.23 & 20 \\
Atns-UGA & 0.71 & 0.86 & 0.74 & 0.75 & 0.28 & 22 \\
Rome & 0.47 & 0.76 & 0.72 & 0.75 & 0.24 & 25 \\
N Birm & 0.52 & 0.92 & 0.70 & 0.73 & 0.23 & 18 \\
Wylam & 0.62 & 0.87 & 0.68 & 0.67 & 0.24 & 18 \\
Aug-Brs & 0.87 & 0.84 & 0.65 & 0.73 & 0.22 & 31 \\
Macon & 0.75 & 0.89 & 0.65 & 0.59 & 0.21 & 24 \\
Col-Crs & 0.54 & 0.88 & 0.62 & 0.62 & 0.24 & 26 \\
Mean & 0.64 & 0.86 & 0.70 & 0.72 & & \\
Std & 0.13 & & 0.07 & 0.09 & & \\
Std/Mean & 0.21 & & 0.10 & 0.13 & & \\
\hline Rural Site & Slope & $r$ & Mean & Median & Stdev & $N$ \\
\hline Ashland & 0.63 & 0.78 & 0.67 & 0.67 & 0.31 & 25 \\
Providence & 0.65 & 0.88 & 0.66 & 0.67 & 0.28 & 14 \\
Crossville & 0.48 & 0.70 & 0.62 & 0.64 & 0.22 & 27 \\
Yorkville & 0.41 & 0.78 & 0.62 & 0.62 & 0.19 & 23 \\
Trenton & 0.65 & 0.92 & 0.60 & 0.62 & 0.17 & 21 \\
Sandersville & 0.67 & 0.91 & 0.57 & 0.50 & 0.20 & 19 \\
Mean & 0.58 & 0.83 & 0.62 & 0.62 & & \\
Std & 0.11 & & 0.04 & 0.06 & & \\
Std/Mean & 0.19 & & 0.06 & 0.10 & & \\
\hline & & & & & &
\end{tabular}

2) In addition to these variables, some FRM stations were also speciation sites (limited to only urban sites, see Table 1), and the factor analysis was repeated with added components OC, EC and selected metals (see supplemental material Figs. S1 and S2, respectively). Positive Matrix Factorization (PMF) resolved four factors in the first case and five factors in the second. The factors were identified as follows. F1: biomass burning due to high fractions of levoglucosan, xylose, WSOC and measured solution absorption at $365 \mathrm{~nm}$ $\left(A_{365}\right.$, which equals $\log _{10}\left(I / I_{o}\right)$ averaged over $\lambda$ of 360 to $370 \mathrm{~nm}$, see Eq. 1), F2: Refractory due to high fractions of magnesium and sodium, F3: Secondary WSOC/Oxalate, with high fractions of WSOC, oxalate, and $A_{365}$, and F4: Secondary Sulfate/WSOC, characterized by ammonium, sulfate, and WSOC. For the speciation sites, the extra variables produced the same four factors, but with an additional factor, F5: Mobile sources, characterized by high EC, OC, iron, and copper. Relative to other factors, F1 (biomass burning) was highest in winter, factors F3 and F4 (secondary) were both highest in summer, and F2 (refractory) and F5 (mobile
Table 2b. Levoglucosan $<50 \mathrm{ng} \mathrm{m}^{-3}$ (mostly Summer data).

\begin{tabular}{lllllll}
\hline Urban Site & Slope & $\mathrm{r}$ & Mean & Median & Stdev & $\mathrm{N}$ \\
\hline Wylam & 0.25 & 0.78 & 0.42 & 0.34 & 0.22 & 41 \\
N Birming & 0.21 & 0.72 & 0.38 & 0.34 & 0.17 & 41 \\
S DeKalb & 0.21 & 0.79 & 0.36 & 0.31 & 0.20 & 35 \\
Atns-UGA & & 0.33 & 0.29 & 0.24 & 0.18 & 26 \\
Aug Brs & 0.13 & 0.79 & 0.28 & 0.27 & 0.11 & 25 \\
Col-Crs & 0.09 & 0.72 & 0.25 & 0.22 & 0.13 & 29 \\
Rome & 0.13 & 0.73 & 0.24 & 0.21 & 0.13 & 30 \\
Macon & 0.18 & 0.86 & 0.21 & 0.21 & 0.08 & 31 \\
Mean & 0.17 & 0.77 & 0.31 & 0.27 & & \\
Std & 0.06 & & 0.07 & 0.05 & & \\
Std/Mean & 0.33 & & 0.24 & 0.20 & & \\
\hline Rural Site & Slope & $r$ & Mean & Median & Stdev & $N$ \\
\hline Providence & 0.13 & 0.56 & 0.32 & 0.23 & 0.22 & 46 \\
Yorkville & 0.12 & 0.75 & 0.30 & 0.26 & 0.15 & 32 \\
Sandersville & 0.15 & 0.73 & 0.29 & 0.26 & 0.15 & 29 \\
Ashland & 0.20 & 0.65 & 0.28 & 0.24 & 0.16 & 35 \\
Crossville & 0.21 & 0.74 & 0.26 & 0.26 & 0.13 & 26 \\
Trenton & 0.13 & 0.74 & 0.26 & 0.22 & 0.16 & 38 \\
Mean & 0.16 & 0.70 & 0.29 & 0.24 & & \\
Std & 0.04 & & 0.02 & 0.02 & & \\
Std/Mean & 0.26 & & 0.08 & 0.08 & & \\
\hline
\end{tabular}

sources) were consistent fractions throughout the year (see Supplementary Figs. 1S and 2S).

In this study of brown carbon sources, the division of absorption amongst these factors is of interest. Figure 7 summarizes the fraction of $A_{365}$ apportioned to the various factors averaged throughout 2007 for all FRM sites and for only urban speciation sites. For both analyses, approximately $55 \%$ of the $A_{365}$ was associated with biomass-burning factor F1. At the urban speciation sites, $13 \%$ of $A_{365}$ was associated with mobile sources. This factor was not resolved in the analysis of all FRM sites since no mobile (traffic) source tracers were available (e.g., EC or metals). A significant fraction of $A_{365}$ was associated with secondary factors. The WSOC/Oxalate factor F3 was 34\% for all FRM sites and $18 \%$ for the urban speciation sites. For the combined secondary factors at the urban speciation sites $(\mathrm{F} 3+\mathrm{F} 4)$ the yearly average fraction was $26 \%$. The $34 \%$ of $A_{365}$ associated with F3 for all FRM sites is likely an upper limit since if mobile source tracers had been included a mobile source factor may have been resolved, lowering F3. However, it is unlikely to be substantially lower since mobile source contributions are low at many of the more rural FRM sites.

Absorption $\left(A_{365}\right)$ associated with secondary WSOC/Oxalate factor F3 is particularly interesting since it is linked to SOA formation (e.g., F3 is much higher in summer) and consistent with photochemical heterogeneous 

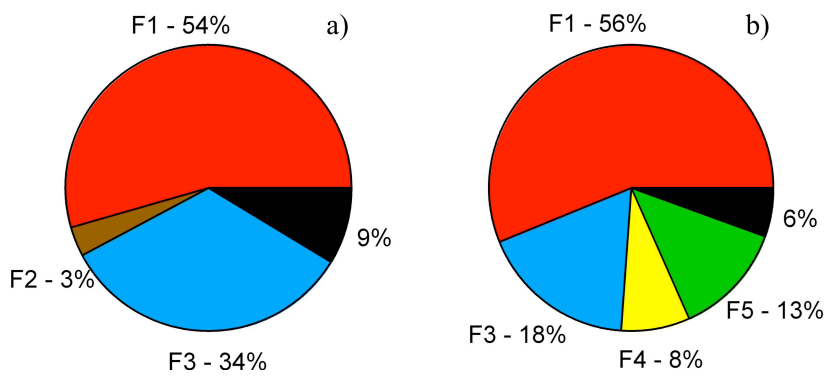

Fig. 7. PMF results on the 2007 average distribution of $A_{365}$ amongst (a) the four factors resolved for all FRM sites (rural and urban) using a limited suite of species, and (b) the five factors resolved for only urban speciation sites listed in Table 1 . The factors were identified (Zhang et al., 2010a) as, F1: Biomass Burning, F2: Refractory Material, F3: WSOC/Oxalate, F4: Ammonium Sulfate/WSOC, F5: Mobile Sources, remaining is the unresolved fraction.

conversion of some fraction of the SOA to chromophores as aerosols age. Oxalate, for example, is known to have a variety of sources, one of the main being production via particle aqueous-phase reactions within cloud or fog drops (Huang et al., 2006; Sorooshian et al., 2006). Heterogeneous conversion of SOA formed in urban or rural locations would readily explain the regional component of light absorbing WSOC recorded throughout the Southeastern US. Summer time contributions from combustion sources (biomass burning or mobile sources) cannot be ruled out, but seem unlikely to account for the $\mathrm{Abs}_{365}$ - WSOC correlation throughout the southeast since both are very minor fractions of summer WSOC. Brown carbon linked to SOA formation or its chemical evolution would most readily explain the light-absorbing component of the water-soluble aerosol fraction observed throughout the Southeastern US during summer.

Results discussed so far from the FRM filters likely do not include semi-volatile species due to the filter sampling method and length of time in storage and so represent the more stable and aged components of the ambient aerosol. They are also highly averaged over time and the variability that drove the PMF analysis is on time scales of days to weeks (FRM 24-h averaged filters collected every 4 days) and so driven more by synoptic scale dynamics. The online measurements are less susceptible to artifacts and can also be used to investigate daily variability of light absorption characteristics relative to WSOC. These measurements focused on non-biomass burning $\mathrm{Abs}_{365}$ and WSOC recorded during summer.

\subsection{Online measurement results: diurnal trends}

Summer patterns in diurnal variability of the absorption coefficient ( $\left.\mathrm{Abs}_{365}\right)$ relative to WSOC and other emissions can provide insight into other non-biomass burning sources of
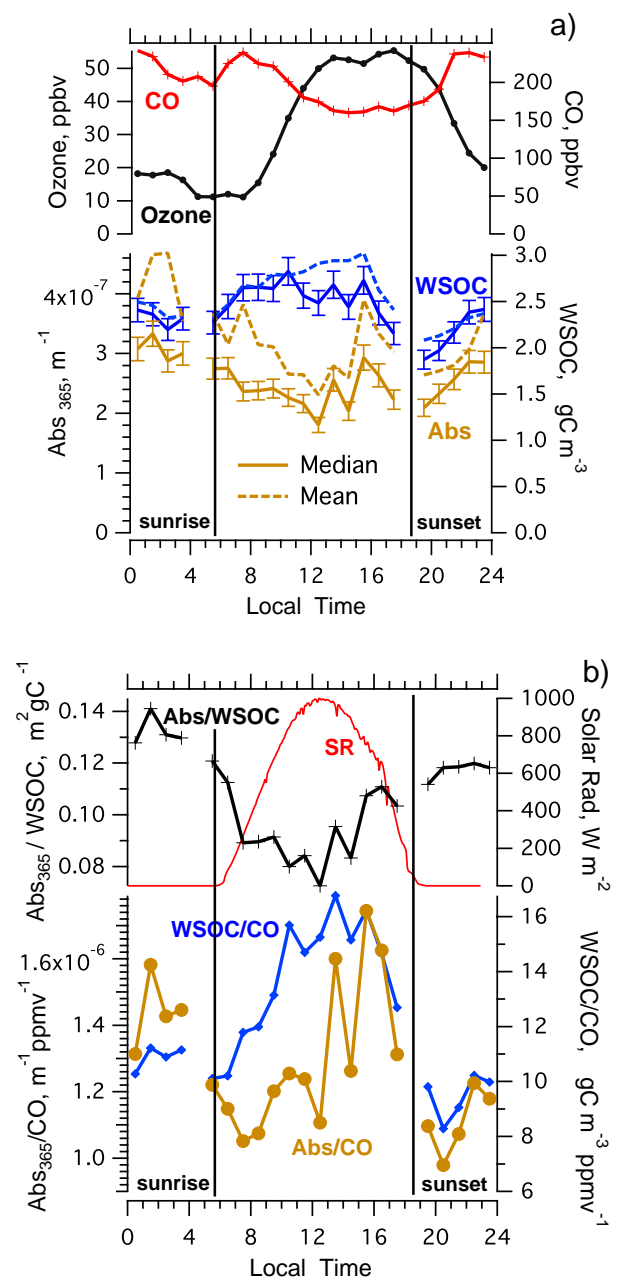

Fig. 8. (a) Hourly medians of Ozone, CO, WSOC and light absorption coefficient at $365 \mathrm{~nm}\left(\mathrm{Abs}_{365}\right)$ from online measurements in Atlanta, GA, 1 July to 15 August 2009. Hourly means of WSOC and $\mathrm{Abs}_{365}$ are also plotted in (a). Variability in WSOC and $\mathrm{Abs}_{365}$ hourly medians is the standard error. Ratios of hourly medians are shown in the plot along with solar radiation on 11 July (b). Gaps at 04:00 and 18:00 are periods of dynamic blanks. Number of data points for each hour used to compute medians or means of Abs365 and WSOC are between 225 and 325.

light-absorbing species. Figure 8 shows the median diurnal trends for data between 1 July to 15 August 2009 for online $\mathrm{Abs}_{365}$ and WSOC data binned into hourly averages. $\mathrm{CO}$ and ozone measured over the same period are included for comparison, but were measured at a different site; the Southern Aerosol Research Characterization Study (SEARCH) monitoring station (Jefferson Street, Atlanta) $\sim 4 \mathrm{~km}$ away.

\subsubsection{Brown carbon and SOA}

$\mathrm{Abs}_{365}$, and WSOC to a greater extent, both show moderate diurnal variability relative to a high background, typical of the regional characteristics of Southeastern US pollutants 
(Zhang et al., 2010b). For WSOC there was a clear daytime increase of $\sim 20$ to $30 \%$ over the average nighttime concentration. This is attributed to photochemical SOA production linked to urban emissions since this increase was not observed at a rural site (Yorkville, GA) $\sim 70 \mathrm{~km}$ from central Atlanta, GA (Zhang et al., 2010b). Although the WSOC daytime increase was small, it is related to substantial production of WSOC given the significant growth in boundary layer height from night to day in the summer (Marsik et al., 1994) and low WSOC concentrations at higher altitudes (Weber et al., 2007) (see (Zhang et al., 2010b) for more details). Evidence of this is indicated by the WSOC/CO ratio, which shows a substantial increase during daytime. A similar daytime WSOC increase has been observed in Atlanta in other summers (Hennigan et al., 2009) and at other urban sites, such as Mexico City (Hennigan et al., 2008), and has been linked to photochemical production.

In contrast to WSOC, the light absorption diurnal trend differed. The rapid increase in WSOC following sunrise was not observed in $\mathrm{Abs}_{365}$ (except for an increase seen in mean $\mathrm{Abs}_{365}$ at morning rush hour, discussed further below). Instead, the absorption coefficient $\left(\mathrm{Abs}_{365}\right)$ generally decreased during the morning, likely due to dilution as the boundary layer expanded, indicating that relatively freshly formed WSOC (e.g., SOA) contained few chromophores at our detection levels. Although there was a small increase in $\mathrm{Abs}_{365} / \mathrm{CO}$ in the morning (Fig. 8b), the median mass absorption efficiency ( $\mathrm{Abs}_{365}$ /WSOC) was on a decreasing trend until approximately noon. Following noon, however, light absorption levels in the aqueous samples began to increase and $\mathrm{Abs}_{365}$ relative to WSOC and CO substantially increased. The lack of corresponding and significant increase in WSOC or CO suggests that the increasing $\mathrm{Abs}_{365}$ was not linked to primary WSOC emissions. It is possible that at this specific time of day some primary source of highly efficient light absorbing compounds (e.g., high $\varepsilon$ ), contributed a very small amount to the overall WSOC concentrations, but accounted for the increase in absorption, although we view this as unlikely. The $\mathrm{Abs}_{365}$ increase began in early afternoon (13:00) and peaked in the 15:00 to $16: 00 \mathrm{~h}$, too early for afternoon rush-hour traffic. Persistent advection of a different aerosol to the sampling site at this time of day also seems unlikely since at the rural site (Yorkville) WSOC had a different diurnal trend (Zhang et al., 2010b). Two plausible explanations are: 1) Heterogeneous photochemical conversion of WSOC to more light absorbing compounds, which would account for the lack of substantial increase in WSOC concentration and increase in mass absorption efficiency $\left(\mathrm{Abs}_{365} / \mathrm{WSOC}\right)$ in the afternoon when oxidant levels were high. The rate of this reaction, however, would have to be much faster than what has been observed in laboratory studies. 2) In the afternoon much more efficient light absorbing SVOCs, (e.g., high $\varepsilon$ ), partitioned to the aerosol and may have contributed a small amount to the overall WSOC concentrations, but accounted for a sig- nificant increase in absorption. In either case, the diurnal trend indicates that fresh SOA formed in the morning did not contain measureable levels of chromophores, however, rapid (within a few hours) heterogeneous conversion, or SOA gas-phase precursors formed in the afternoon during periods of higher oxidant concentrations do produce water-soluble chromophores. These processes appear to be substantial given that the magnitude of the afternoon $\mathrm{Abs}_{365}$ increases during a period when the summertime boundary layer is deep and well mixed.

\subsubsection{Primary brown carbon from vehicles}

There is also evidence of a primary and/or nonphotochemical source of light-absorbing WSOC components. The summer median $\mathrm{Abs}_{365}$ and mass absorbing efficiencies ( $\mathrm{Abs}_{365} / \mathrm{WSOC}$ ratios) increased following sunset and were consistently higher at night. The trend is somewhat similar to $\mathrm{CO}$ and so could be linked to primary emissions (e.g., vehicle fossil fuel combustion) and diurnal trends in boundary layer height, accounting for the concentrating effect after sunset. In Fig. 8, the morning rush-hour (07:00) peak in mean $\mathrm{Abs}_{365}$ and minor change in WSOC indicate a primary combustion source of chromophores of high mass absorption efficiency. Some portion of the nighttime increase, however, could also be linked to production of secondary light absorbing organics through nitrate radical chemistry, especially with biogenic VOC emissions (Brown et al., 2009). Dark aqueous reactions involving ammonium salts, which are ubiquitous in the southeast, leading to light absorbing products are also possible (e.g., (Noziere et al., 2009; Sareen et al., 2010)).

Differences between sites for the FRM filter data also give some evidence for an anthropogenic brown carbon source. On average, sites with highest mass absorption efficiencies determined either from $\mathrm{Abs}_{365} / \mathrm{WSOC}$ average ratios or slopes, such as Birmingham and DeKalb (Table 2b), are also sites more impacted by anthropogenic emissions. For example, when levoglucosan was less than $50 \mathrm{ng} \mathrm{m}^{-3}$, mean $\mathrm{EC}$ at Birmingham and DeKalb was $\sim 1.3 \mu \mathrm{gC} \mathrm{m} \mathrm{m}^{-3}$, compared to 0.5 to $0.7 \mu \mathrm{gC} \mathrm{m}^{-3}$ at Atns-UGA, Aug-Brs, Col-Crs, Rome, and Macon. However, a statistically significant difference in mean $\mathrm{Abs}_{365}$ /WSOC ratio between pairs of sites was only found for $\mathrm{N}$ Birmingham and other sites (typically t-test $p<0.01$, except with DeKalb, $p=0.84$ ). Difference in mean $\mathrm{Abs}_{365}$ /WSOC ratios between other urban versus urban $(p>0.3)$, rural versus rural $(p>0.4)$, or rural-urban $(p>0.3)$ pairs were generally not statistically significant.

Overall, the inferences based on summer diurnal trends are consistent with the PMF analysis and comparisons between sites; that apart from biomass burning, a significant component of the yearly-average $\mathrm{Abs}_{365}$ was associated with secondary formation processes and that mobile sources (e.g., internal combustion engines) was also a source for brown carbon, but mainly in urban settings. 


\section{Summary}

Light absorption spectra over wavelengths of $200-800 \mathrm{~nm}$ were recorded for water-soluble components of ambient fine $\left(\mathrm{PM}_{2.5}\right)$ particles using a spectrophotometer with 1$\mathrm{m}$ long Liquid Waveguide Capillary Cell for high sensitivity. Absorption spectra had the brown carbon spectral characteristic of rapidly increasing absorption with decreasing wavelengths, at wavelengths below $\sim 400 \mathrm{~nm}$. Based on a power law fit, Ångstrom exponents were similar for biomass and non-biomass-burning-influenced ambient samples and ranged between 6 and 8; similar to that reported for aqueous samples of biomass burning HULIS and fresh SOA from ozonolysis of terpenes.

Seasonal data based on water-soluble components extracted from FRM filters throughout the Southeastern US showed that biomass burning was the most significant source of brown carbon during the colder months. At these times, absorption by brown carbon was highest and highly correlated with levoglucosan. Mass absorption efficiencies based on ratios of light absorption at $365 \mathrm{~nm}$ to WSOC from linear regression slopes, or average of Absorption /WSOC ratios, both indicated that the fraction of chromophores in the WSOC was $\sim 3$ times higher when biomass burning was prevalent compared to the non-biomass burning warmer summer periods. In contrast, a fairly consistent lightabsorbing component of WSOC was also observed throughout the southeast in summer and correlated to WSOC mass. During summer, there was evidence for both primary and secondary sources. Primary WSOC from mobile sources (e.g., fossil fuel combustion) may account for the slightly higher mass absorption efficiencies observed at the more polluted urban sites, however, the widespread regional brown carbon was more likely related to aged SOA. Average diurnal trends indicated that fresh secondary WSOC formed in the morning contained no measurable levels of chromophores that absorbed at $365 \mathrm{~nm}$, however, in the afternoon during periods of higher oxidant levels the fraction of chromophores substantially increased relative to water-soluble carbon mass. A factor analysis of the 24-h filter data linked much of the brown carbon throughout the southeast in summer to an oxalate source, consistent with aqueous heterogeneous conversion of some components of SOA to chromophores. It is not clear from this data set if the afternoon increase in light absorbing components were from a similar process, however, an earlier study in Atlanta has linked WSOC formation to aerosol liquid water (Hennigan et al., 2009). If the afternoon increase in WSOC (i.e., SOA) mass absorbing efficiency was due to chemical aging, the production of chromophores was much faster (within hours) than what has currently been reported (days). Instead, the afternoon increase in $\mathrm{Abs}_{365}$ /WSOC could have been due to partitioning of chemically different SVOCs at that time.

A number of investigators have shown evidence for chemical evolution of SOA. In Atlanta we found that fresher
WSOC, observed during periods of photochemical smog, contained higher fractions of hydrophilic WSOC (e.g., low molecular weight acids and carbonyls, among other things), relative to a persistent fraction of WSOC $(\sim 50 \%)$ with properties of HULIS (e.g., higher molecular weight, more surface active and light absorbing) (Sullivan and Weber, 2006b, a). The evolution of fresh SOA to higher mass absorbing efficiencies reported in this study is consistent with those results. In other regions, SOA has been found to rapidly evolve to a lower volatile more oxygenated state (DeCarlo et al., 2010). Many of the observed changes in SOA reported in this and other studies may result from a common chemical aging mechanism. In the Southeastern US a mechanism consistent with our various studies is aqueous phase chemical conversion. Alternatively, properties associated with HULIS could just simply represent common characteristics of an aged aerosol that reaches that state through many different processes.

\section{Supplementary material related to this article is available online at: http://www.atmos-chem-phys.net/10/5965/2010/ acp-10-5965-2010-supplement.pdf.}

Acknowledgements. The authors thank Susan Zimmer-Dauphinee of the Georgia Department of Natural Resources (GA DNR), Tracy Anderson of the Alabama Department of Environmental Management, Randy Dillard of the Alabama Jefferson Co. Department of Health, and Scott Reynolds of the South Carolina Department of Health and Environmental Control for providing the FRM filters analyzed in this study. This work was supported by the GA DNR under grant No. 773-80150 and a National Science Foundation grant ATM-0802237. The authors also thank Dr. Amy Sullivan for providing mannosan and galactosan standard stock solutions, Jiumeng Liu for the WSOC analysis and Thomas Muccillo for assistance in measurement of absorption spectra. The information expressed in this paper does not necessarily reflect the policies of the US Environmental Protection Agency.

Edited by: F. McNeill

\section{References}

Andreae, M., and Gelencser, A.: Black carbon or brown carbon? The nature of light-absorbing carbonaceous aerosols, Atmos. Chem. Phys., 6, 3131-3148, doi:10.5194/acp-6-3131-2006, 2006.

Asa-Awuku, A., Sullivan, A., Hennigan, C., Weber, R. J., and Nenes, A.: Investigation of molar volume and surfactant characteristics of water-soluble organic compounds in biomass burning aerosol, Atmos. Chem. Phys., 8, 799-812, doi:10.5194/acp-8799-2008, 2008.

Belz, M., Dress, P., Sukhitskiy, A., and Liu, S.: Linearity and effective optical pathlength of liquid waveguide capillary cells, SPIEIE Conference on Internal Standardization and Calibration Architectures for Chemical Sensors, Boston Massachusetts, September, 3856, 271-281, 1999. 
Birch, M. E. and Carey, R. A.: Elemental Carbon-Based Method for Monitoring Occupational Exposures to Particulate Diesel Exhaust, Aerosol Sci. Tech., 25, 221-241, 1996.

Bond, T. C.: Spectral dependence of visible light absorption by carbonaceous particles emitted from coal combustion, Geophys. Res. Lett., 28, 4075-4078, 2001.

Bones, D. L., Henricksen, D. K., Mang, S. A., Gonsior, M., Bateman, A. P., Nguyen, T. B., Cooper, W. J., and Nizkorodov, S. A.: Appearance of strong absorbers and fluorophores in limoneneO3 secondary organic aerosol due to NH4+-mediated chemical aging over long time scales, J. Geophys. Res., 115, D05203, doi:10.1029/02009JD012864, 2010.

Brown, S. S., deGouw, J. A., Warneke, C., Ryerson, T. B., Dube, W. P., Atlas, E., Weber, R. J., Peltier, R., Neuman, J. A., Roberts, J. M., Swanson, A., Flocke, F., McKeen, S. A., Brioude, J., Sommariva, R., Trainer, M., Fehsenfeld, F. C., and Ravishankara, A. R.: Nocturnal isoprene oxidation over the Northeastern United States and its impact on reactive nitrogen partitioning and secondary organic aerosol, Atmos. Chem. Phys., 9, 3027-3042, doi:10.5194/acp-9-3027-2009, 2009.

Chen, Y., and Bond, T. C.: Light absorption by organic carbon from wood combustion, Atmos. Chem. Phys., 10, 1773-1787, doi:10.5194/acp-10-1773-2010, 2010.

Chow, J. C., Watson, J. G., Chen, L.-W. A., Arnott, W. P., Moosmuller, H., and Fung, K.: Equivalence of elemental carbon by thermal/optical reflectance and transmittance with different temperature protocols, Environ. Sci. Technol., 38, 4414-4422, 2004.

de Haan, D. O., Corrigan, A. L., Smith, K. W., Stroik, D. R., Turley, J. J., Lee, F. E., Tolbert, M. A., Jimenez, J. L., Cordova, K. E., and Ferrell, G. R.: Secondary organic aerosol-forming reactions of glyoxal with amino acids, Environ. Sci. Tech., 43, 2818-2824, 2009a.

de Haan, D. O., Tolbert, M. A., and Jimenez, J. L.: Atmospheric condensed-phase reactions of glyoxal with methylamine, Geophys. Res. Lett., 36, L11819, doi:11810.11029/12009GL037441, 2009b.

DeCarlo, P. F., Ulbrich, I. M., Crounse, J., Foy, B. d., Dunlea, E. J., Aiken, A. C., Knapp, D., Weinheimer, A. J., Campos, T., Wennberg, P. O., and Jimenez, J. L.: Investigation of the sources and processing of organic aerosol over the Central Mexican Plateau from aircraft measurements during MILAGRO, Atmos. Chem. Phys., 10, 5257-5280, doi:10.5194/acp-10-52572010, 2010.

Decesari, S., Facchini, M. C., Fuzzi, S., and Tagliavini, E.: Characterization of water-soluble organic compounds in atmospheric aerosol: A new approach, J. Geophys. Res., 105, 1481-1489, 2000.

Duarte, R. M. B. O., Pio, C. A., and Duarte, A. C.: Spectroscopic study of the water-soluble organic matter isolated from atmospheric aerosols collected under different atmospheric conditions, Analytica Chimica Acta, 530, 7-14, 2005.

Eatough, D. J., Wadsworth, A., Eatough, D. A., Crawford, J. W., Hansen, L. D., and Lewis, E. A.: A mulitple-system, multichannel diffusion denuder sampler for the determination of fineparticulate organic material in the atmosphere, Atmos. Environ., 27A, 1213-1219, 1993.

Facchini, M. C., Decesari, S., Mircea, M., Fuzzi, S., and Loglio, G.: Surface tension of atmospheric wet aerosol and cloud/fog droplets in relation to their organic carbon content and chemical compostion, Atmos. Environ., 34, 4853-4857, 2000.

Graber, E. R., and Rudich, Y.: Atmospheric HULIS: How humiclike are they? A comprehensive and critical review, Atmos. Chem. Phys., 6, 729-735, doi:10.5194/acp-6-729-2006, 2006.

Hamilton, J. F., Webb, P. J., Lewis, A. C., Hopkins, J. R., Smith, S., and Davy, P.: Partially oxidised organic components in urban aerosol using GCXGC-TOF/MS, Atmos. Chem. Phys., 4, 12791290, doi:10.5194/acp-4-1279-2004, 2004.

Hansen, A. D. A. and Novakov, T.: Real-time measurement of aerosol black carbon during the carbonaceous species methods comparison study, Aerosol Sci. Tech., 12, 194-199, 1990.

Havers, N., Burba, P., Lambert, J., and Klockow, D.: Spectroscopic characterization of humic-like substances in airborne particulate matter, J. Atmos. Chem., 29, 45-54, 1998.

Hennigan, C. J., Sullivan, A. P., Fountoukis, C. I., Nenes, A., Hecobian, A., Vargas, O., Hanks, A. T. C., Huey, L. G., Lefer, B. L., Russell, A. G., and Weber, R. J.: On the volatility and production mechanisms of newly formed nitrate and water soluble organic aerosol in Mexico City, Atmos. Chem. Phys., 8, 37613768, doi:10.5194/acp-8-3761-2008, 2008.

Hennigan, C. J., Bergin, M. H., Russell, A. G., Nenes, A., and Weber, R. J.: Gas/particle partitioning of water-soluble organic aerosol in Atlanta, Atmos. Chem. Phys., 9, 3613-3628, doi:10.5194/acp-9-3613-2009, 2009.

Hoffer, A., Kiss, G., Blazso, M., and Gelencser, A.: Chemical characterization of humic like substances (HULIS) formed from a lignin-type precursor in model cloud water, Geophys. Res. Lett., 31, L06115, doi 10.1029/2003GL018962, 2004.

Hoffer, A., Gelencser, A., Guyon, P., Kiss, G., Schmid, O., Frank, G. P., Artaxo, P., and Andreae, M. O.: Optical properties of humic-like substances (HULIS) in biomass-burning aerosols, Atmos. Chem. Phys., 6, 3563-3570, doi:10.5194/acp-6-3563-2006, 2006.

Huang, X.-F., He, J., and Yuan, Z.: Water-soluble organic carbon and oxalate in aerosols at a coastal urban site in China: Size distribution characteristics, sources, and formation mechanisms, J. Geophys. Res., 111, D22212, doi:22210.21029/22006JD007484, 2006.

Iinuma, Y., Engling, G., Puxbaum, H., and Herrmann, H.: A highly resolved anion exchange chromatographic method for determination of saccharidic tracers for biomass combustion and primary bio-particles in atmospheric aerosol, Atmos. Environ., 43, 13671371, 2009.

Kirchstetter, T. W., Novakov, T., and Hobbs, P. V.: Evidence that the spectral dependence of light absorption by aerosols is affected by organic carbon, J. Geophys. Res., 109, D21208, doi:10.1029/22004JD004999., 2004.

Kiss, G., Tombacz, E., Varga, B., Alsberg, T., and Persson, L.: Estimation of the average molecular weight of humic-like substances isolated from fine atmspheric aerosol, Atmos. Environ., 37, 3783-3794, 2003.

Kondo, Y., Miyazaki, Y., Takegawa, N., Miyakawa, T., Weber, R. J., Jimenez, L., Zhang, Q., and Worsnop, D. R.: Oxygenated and water-soluble organic aerosols in Tokyo, J. Geophys. Res., 112, D01203, 01210.01029/02006JD007056, 2007.

Limbeck, A., Kulmala, M., and Puxbaum, H.: Secondary organic aerosol formation in the atmosphere via heterogeneous reaction of gaseous isoprene on acidic particles, Geophys. Res. Lett., 30, ASC 6-1-6-4, doi:10.1029/2003GL017738, 2003. 
Lukacs, H., Gelencser, A., Hammer, S., Puzbaum, H., Pio, C., Legrand, M., Kasper-Giebl, A., Handler, M., Limbeck, A., Simpson, D., and Preunkert, S.: Seasonal trends and possible sources of brown carbon based on 2-year aerosol measurements at six sites in Europe, J. Geophys. Res., 112, D23S18, doi:10.1029/2006JD008151, 2007.

Marley, N. A., Gaffney, J. S., Tackett, M., Sturchio, N. C., Heraty, L., Martinez, N., Hardy, K. D., Marchany-Rivera, A., Guilderson, T., MacMillan, A., and Steelman, K.: The impact of biogenic carbon sources on aerosol absorption in Mexico City, Atmos. Chem. Phys., 9, 1537-1549, doi:10.5194/acp-9-1537-2009, 2009.

Marsik, F. J., Fischer, K. W., McDonald, T. D., and Samson, P. J.: Comparison of methods for estimating mixing height used during the 1992 Atlanta Field Intensive, J. Applied Meteor., 34, 1802-1814, 1994.

Miyazaki, Y., Kondo, Y., Takegawa, N., Komazaki, Y., Kawamura, K., Mochida, M., Okuzawa, K., and Weber, R. J.: Time-resolved measurements of water-soluble organic carbon in Tokyo, J. Geophys. Res., 111, D23206, doi:23210.21029/22006JD007125, 2006.

Noziere, B., and Esteve, W.: Organic reactions increasing the absorption index of atmosheric sulfuric acid aerosols, J. Geophys. Res., 32, L03812, doi:10.1029/2004GL021942, 2005.

Noziere, B., Dziedzic, P., and Cordova, A.: Formation of secondary light-absorbing "fulvic-like" oligomers: A common process in aqueous and ionic atmosphric particles?, Geophys. Res. Lett., 34, L21812, doi:10.1029/22007GL031300, 2007.

Noziere, B., Dziedzic, P., and Cordova, A.: Products and kinetics of the liquid-phase reation of glyoxal catalyzed by ammonium ions (NH4+), J. Phys. Chem. A, 113, 231-237, 2009.

Puxbaum, H., Caseiro, A., Sanchez-Ochoa, A., Kasper-Giebl, A., Claeys, M., Gelencser, A., Legrand, M., Preunkert, S., and Pio, C.: Levoglucosan levels at background sites in Europe for assessing the impact of biomass combustion on the European aerosol background, J. Geophys. Res., 112, D23S05, doi:10.1029/2006JD008114, 2007.

Rosen, H., Hansen, A. D. A., Dod, R. L., and Novakov, T.: Soot in urban atmspheres: Determination by an optical absorption technique, Science, 208, 741-744, 1980.

Sareen, N., Schwier, A. N., Shapiro, E. L., Mitroo, D., and McNeil, V. F.: Secondary organic material formed by methylglyoxal in aqueous aerosol mimics, Atmos. Chem. Phys., 10, 997-1016, doi:10.5194/acp-10-997-2010, 2010.

Seinfeld, J. H. and Pankow, J. F.: Organic atmospheric particulate material, Ann. Rev. Phys. Chem., 54, 121-140, 2003.

Shapiro, E. L., Szprengiel, J., Sareen, N., Jen, C. N., Giordano, M. R., and McNeill, V. F.: Light-absorbing secondary organic material formed by glyoxal in aqueous aerosol mimics, Atmos. Chem. Phys., 9, 2289-2300, doi:10.5194/acp-9-2289-2009, 2009.

Sorooshian, A., Varutbangkul, V., Brechtel, F. J., Ervens, B., Feingold, G., Bahreine, R., Murphy, S. M., Holloway, J. S., Atlas, E. L., Buzorius, G., Jonsson, H., Flagan, R. C., and Seinfeld, J. H.: Oxalic acid in clear and cloudy atmospheres: Analysis of data from International Consortium for Atmospheric Research on Transport and Transformation 2004, J. Geophys. Res., 111, D23S45, doi:10.1029/2005JD006880, 2006.
Sullivan, A., Peltier, R. E., Brock, C. A., Gouw, J. A. d., Holloway, J. S., Warneke, C., Wollny, A. G., and Weber, R. J.: Airborne measurements of carbonaceous aerosol soluble in water over northeastern United States: Method development and an investigation into water-soluble organic carbon sources, J. Geophys. Res., 111, D23S46, doi:10.1029/2006JD007072, 2006.

Sullivan, A. and Weber, R. J.: Chemical characterization of the ambient organic aerosol soluble in water Part 1: Isolation of hydrophobic and hydrophilic fractions with a XAD-8 resin, J. Geophys. Res., 111, D05314, doi:10.1029/02005JD006485, 2006a.

Sullivan, A. and Weber, R. J.: Chemical characterization of the ambient organic aerosol soluble in water Part 2: Isolation of acid, neutral, and basic fractions by modified size exclusion chromatography, J. Geophys. Res., 111, D05315, doi:10.1029/02005JD006486, 2006b.

Sullivan, A. P., R. J. Weber, Clements, A. L., Turner, J. R., Bae, M. S., and Schauer, J. J.: A method for on-line measurement of water-soluble organic carbon in ambient aerosol particles: Results from an urban site, Geophys. Res. Lett., 31, L13105, doi:10.1029/12004GL019681, 2004.

Turpin, B. J., Cary, R. A., and Huntzicker, J. J.: An in situ, time-resolved analyzer for aerosol organic and elemental carbon, Aerosol Sci. Tech., 12, 161-171, 1990.

Varga, B., Kiss, G., Ganszky, I., Gelencser, A., and Krivacsy, Z.: Isolation of water-soluble organic matter from atmospheric aerosol, Talanta, 55, 561-572, 2001.

Weber, R. J., Sullivan, A. P., Peltier, R. E., Russell, A., Yan, B., Zheng, M., Gouw, J. A. d., Warneke, C., Brock, C., Holloway, J. S., Atlas, E. L., and Edgerton, E.: A study of secondary organic aerosol formation in the anthropogenicinfluenced southeastern United States, J. Geophys. Res., 112, D13302, doi:10.1029/12007JD008408, 2007.

Yan, B., Zheng, M., Hu, Y., Ding, X., Sullivan, A., Weber, R., Baek, J., Edgerton, E. S., and Russell, A. G.: Roadside, urban and rural comparison of primary and secondary organic molecular markers in ambient $\mathrm{PM}_{2.5}$, Environ. Sci. Technol., es-2009-00316g, 2009.

Yang, M., Howell, S. G., Zhuang, J., and Huebert, B. J.: Attribution of aerosol light absorption to black carbon, brown carbon, and dust in China - Interpretations of atmospheric measurements during EAST-AIRE, Atmos. Chem. Phys., 9, 2035-2050, doi:10.5194/acp-9-2035-2009, 2009.

Zhang, Q., Worsnop, D. R., Canagaratna, M. R., and Jimenez, J.L.: Hydrocarbon-like and oxygenated organic aerosols in Pittsburgh: Insights into sources and process of organic aerosols, Atmos. Chem. Phys., 5, 8421-8471, doi:10.5194/acp-5-3289-2005, 2005.

Zhang, X., Hecobian, A., Zheng, M., Frank, N., and Weber, R. J.: Biomass buring impact on $\mathrm{PM}_{2.5}$ over the southeastern $\mathrm{U}$. S.: Intgrating chemically speciated FRM filter measurements, MODIS fire counts and PMF analysis, Atmos. Chem. Phys. Discuss., 10, 7037-7077, doi:10.5194/acpd-10-7037-2010, 2010a.

Zhang, X., Hecobian, A., Zheng, M., Frank, N., and Weber, R. J.: On the spatial variability of fine particle water-soluble organic carbon in the Southeastern United States, Atmos. Chem. Phys., in preparation, $2010 \mathrm{~b}$. 